\title{
Specific NOTCH1 antibody targets DLL4-induced proliferation, migration, and angiogenesis in NOTCH1-mutated CLL cells
}

\author{
Mónica López-Guerra ${ }^{1,2,3} \cdot$ Sílvia Xargay-Torrent ${ }^{1}$ • Patricia Fuentes ${ }^{4} \cdot$ Jocabed Roldán $^{1,2,3}$. \\ Blanca González-Farré2,3,5 • Laia Rosich ${ }^{1,3}$. Elisabeth Silkenstedt ${ }^{1,6}$ • María J. García-León ${ }^{7}$. Eriong Lee-Vergés ${ }^{1,3}$. \\ Neus Giménez ${ }^{1,3}$ - Ariadna Giró ${ }^{1,3}$ - Marta Aymerich ${ }^{1,2,3} \cdot$ Neus Villamor $^{2,3} \cdot$ Julio Delgado $^{3,8}$. \\ Armando López-Guillermo ${ }^{3,5,8} \cdot$ Xose S. Puente $\mathbb{D}^{3,9} \cdot$ Elias Campo $\mathbb{D}^{2,3,5} \cdot$ María L. Toribio $\mathbb{D}^{4}$. \\ Dolors Colomer (iD) $1,2,3,5$
}

Received: 18 September 2018 / Revised: 10 September 2019 / Accepted: 1 October 2019 / Published online: 15 October 2019

(c) The Author(s) 2019. This article is published with open access

\begin{abstract}
Targeting Notch signaling has emerged as a promising therapeutic strategy for chronic lymphocytic leukemia (CLL), particularly in NOTCH1-mutated patients. We provide first evidence that the Notch ligand DLL4 is a potent stimulator of Notch signaling in NOTCH1-mutated CLL cells while increases cell proliferation. Importantly, DLL4 is expressed in histiocytes from the lymph node, both in NOTCH1-mutated and -unmutated cases. We also show that the DLL4-induced activation of the Notch signaling pathway can be efficiently blocked with the specific anti-Notch1 antibody OMP-52M51. Accordingly, OMP-52M51 also reverses Notch-induced $M Y C, C C N D 1$, and NPM1 gene expression as well as cell proliferation in NOTCH1-mutated CLL cells. In addition, DLL4 stimulation triggers the expression of protumor target genes, such as $C X C R 4, N R A R P$, and $V E G F A$, together with an increase in cell migration and angiogenesis. All these events can be antagonized by OMP-52M51. Collectively, our results emphasize the role of DLL4 stimulation in NOTCH1-mutated CLL and confirm the specific therapeutic targeting of Notch1 as a promising approach for this group of poor prognosis CLL patients.
\end{abstract}

These authors contributed equally: Mónica López-Guerra, Sílvia Xargay-Torrent

Supplementary information The online version of this article (https:// doi.org/10.1038/s41388-019-1053-6) contains supplementary material, which is available to authorized users.

Dolors Colomer

dcolomer@clinic.cat

1 Experimental Therapeutics in Lymphoid Malignancies Group, Institut d'Investigacions Biomèdiques August Pi i Sunyer (IDIBAPS), Barcelona, Spain

2 Hematopathology Section, Hospital Clínic, Institut d'Investigacions Biomèdiques August Pi i Sunyer (IDIBAPS), Barcelona, Spain

3 Centro de Investigación Biomédica en Red de Cáncer (CIBERONC), Barcelona, Spain

4 Centro de Biología Molecular Severo Ochoa, Consejo Superior de Investigaciones Científicas, Universidad Autónoma de Madrid, Madrid, Spain

\section{Introduction}

Activating mutations in NOTCHI have emerged as one of the most frequent somatic alterations in chronic lymphocytic leukemia (CLL), affecting up to $10-15 \%$ of patients at diagnosis [1,2]. Clinically, NOTCH1-mutated patients have features associated with adverse prognosis and high risk of transformation [2-4]. The majority of these mutations

5 Universitat de Barcelona, Barcelona, Spain

6 Department of Internal Medicine III, University Hospital, Ludwig Maximilian University, Munich, Germany

7 Institut d'Hématologie-Immunologie, INSERM U1109, Strasbourg, France

8 Hematology Department, Hospital Clínic, Institut d'Investigacions Biomèdiques August Pi i Sunyer (IDIBAPS), Barcelona, Spain

9 Departamento de Bioquímica y Biologí, a MolecularInstituto Universitario de Oncología, Universidad de Oviedo, Oviedo, Spain 
abrogate the PEST domain and generate a truncated protein that accumulates in the cell and activates downstream signaling [2]. More recently, recurrent mutations in the noncoding 3'UTR of NOTCHI have been identified in $\sim 3 \%$ of CLL patients, which cause aberrant splicing events that lead to the loss of the PEST domain and increase Notch1 activity [5]. The functional effect of the different types of NOTCHI mutations has been extensively studied in T-acute lymphoblastic leukemia (T-ALL), where most Notch1 alterations affect the heterodimerization domain of the receptor and lead to a constitutive ligand-independent Notch activation [6]. In contrast, both PEST and 3'UTR mutations described in CLL are considered as weak NOTCH1 mutations, not oncogenic by themselves, and are liganddependent $[5,6]$.

Jagged and Delta-like ligands interact with Notch receptors to induce their cleavage and nuclear translocation of the intracellular domain. Once in the nucleus, Notch activates the transcription of target genes including HESI and $M Y C$. Notch1 target genes regulate key biological processes such as development, cell differentiation, cell-fate decisions, proliferation, and apoptosis [7]. In CLL, autocrine and paracrine mechanisms of Notch activation have been suggested, as both tumor CLL lymphocytes as well as cells from the microenvironment express Notch ligands, particularly Jagged 1 and Jagged2 [8, 9]. However, knowledge about the role of Delta-like ligands in CLL is still limited. Although NOTCHI mutations have a prominent role in the pathogenesis of CLL, alternative nonmutational mechanisms of NOTCHI activation have been recently described in CLL [10], indicating that the constitutive activation of the pathway in this leukemia is more frequent than it was first estimated by the incidence of the main recurrent genetic lesions. For this reason, targeting Notch signaling has emerged as a promising therapeutic strategy for CLL, with the hypothesis that its inhibition might also provide an improvement in the efficacy of the standard chemotherapy. Our group previously reported the antitumor effect of the $\gamma$-secretase inhibitor (GSI) PF-03084014 in combination with fludarabine in CLL cells carrying NOTCH1 mutations [11]. Similarly, a marked in vitro resistance to drug-induced apoptosis in CLL cells harboring NOTCH1 mutations has been reported, which may be abrogated by GSI [8]. Moreover, the combination of PF03084014 and fludarabine is able to reduce angiogenesis and CXCL12-induced responses in NOTCH1-mutated CLL cells, in particular those related to tumor migration and invasion [11]. Although preclinical and clinical data using GSIs are encouraging, the main limitations of GSI treatment include nonselectivity and gastrointestinal toxicity [12]. In the last years, antibodies against the specific Notch receptors have been developed, with the idea of avoiding these undesirable side effects [12]. Targeting the individual Notch1 receptor has shown promising preclinical results in T-ALL [13-15], indicating the need to explore this therapeutic strategy in other models of lymphoid malignancies. In this context, the aim of the present study was to define the role of Delta-like ligand stimulation in NOTCHI-mutated CLL cells as well as to explore the therapeutic disruption of this signaling with a specific anti-NOTCH1 antibody.

\section{Results}

\section{DLL4 is a potent stimulator of Notch signaling and proliferation in NOTCH1-mutated CLL}

To evaluate the effect of Notch ligands in CLL, we first stimulated primary CLL cells with the recombinant ligands Jagged1, Jagged2, DLL1, and DLL4 at $10 \mu \mathrm{g} / \mathrm{mL}$. To obtain a potent activation of Notch1 the excess of soluble ligand was not removed, indicating that most of the agonistic effect was due to the remaining soluble ligand. After $24 \mathrm{~h}$ we analyzed the expression of the active form of Notch1 by Western blot. As shown in Fig. 1a, cleaved Notch1 was detected at basal levels in cells from NOTCH1-mutated cases, and, after stimulation with soluble Notch ligands, this activated form of Notch1 increased particularly after Deltalike ligand stimulation. In NOTCHI-unmutated CLL, as previously described [2], no basal cleaved Notch1 was detected, although DLL4 and DLL1 were able to activate Notch1. To further confirm the potent stimulation of Notch signaling by Delta-like ligands in an immobilized model, we cocultured primary CLL cells with the stromal cells OP9 expressing the different human Notch ligands Jagged1 (OP9-JAG1), DLL1 (OP9-DLL1), and DLL4 (OP9-DLL4). After $24 \mathrm{~h}, \mathrm{NOTCH1}$-mutated CLL cells cocultured with OP9-DLL4 showed the strongest activation of Notch1 in comparison with the other ligands (Fig. 1b), suggesting that DLL4 could be the main ligand responsible for Notch activation in CLL both under soluble and immobilized conditions.

Next, we sought to determine whether Notch stimulation had a functional relationship with CLL proliferation. To this aim, we used a CFSE-based assay to monitor the proliferation of CLL cells after a 6-days exposure with $\mathrm{CpG}$ oligodeoxynucleotide (ODN-2006) and IL-15, as both factors collaborate in promoting in vitro CLL growth [16]. We showed that proliferation induction resulted to be significant only in NOTCH1-mutated CLL cells stimulated with Deltalike ligands, especially with DLL4 $(p=0.001)$, consistent with cleaved Notch1 expression (Fig. 1c). Interestingly, this functional effect was specific for NOTCHI-mutated cells and was almost undetected in unmutated cases. All these 

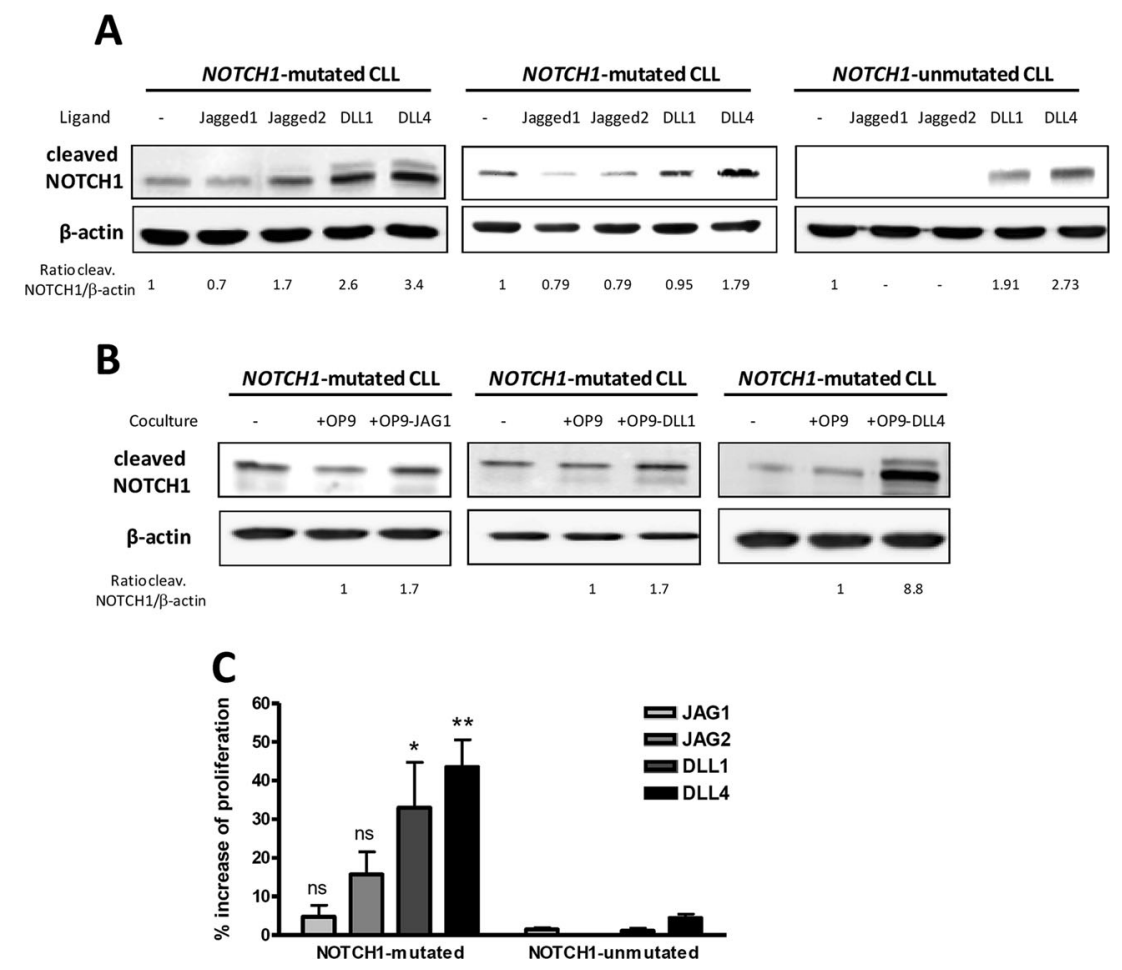

Fig. 1 DLL4 is a potent stimulator of Notch pathway and proliferation in NOTCH1-mutated CLL. Cells from NOTCH1-mutated and -unmutated CLL cases were stimulated with Jagged1 (JAG1), Jagged2 (JAG2), DLL1, and DLL4 (10 $\mu \mathrm{g} / \mathrm{ml})$ ligands (a) or stromal cells OP9JAG1, OP9-DLL1, and OP9-DLL4 (b). Cleaved Notch1 was analyzed by Western blot at $24 \mathrm{~h}$ and densitometrically quantified. $\beta$-Actin was probed as a loading control. Representative cases are shown (CLL 6, 9, and 18). c CFSE-labeled CLL cells were incubated with ODN-2006 and IL-15 together with JAG1, JAG2, DLL1, or DLL4. Reduction of CFSE fluorescence in viable CLL cells was quantified after 6 days by flow cytometry. Graph shows the percentage of cell proliferation induction of each ligand with respect to the unstimulated control. Mean \pm SEM of all the samples analyzed $(n=6$ NOTCH1-mutated and $n=6$ NOTCH1-unmutated). ${ }^{*} p<0.01 ; * p<0.05$, ns not significant results indicated a particular sensitivity of CLL cells to DLL4 stimulation.

\section{DLL4 is expressed in the CLL lymph node}

In view of the remarkable in vitro effect of DLL4 in NOTCH1-mutated CLL, we sought to characterize which cells could express this ligand and trigger the activation of Notch in vivo. We analyzed the expression of DLL4 in the different cellular populations present in lymph nodes (LN) infiltrated by CLL, using immunofluorescence staining and confocal microscopy and tonsil biopsies as controls. In tonsils, we observed coexpression of DLL4 with the monocytic marker CD68 in some histiocytes (Fig. 2). Although tissue architecture is completely effaced in CLL LN, we found that the Notch ligand DLL4 was widely expressed in the vascular endothelium (Supplemental Fig. 1) and, importantly, it was also expressed by some CD68+ cells in both NOTCH1-mutated and -unmutated cases (Fig. 2). All these results suggested that DLL4 is expressed in the lymph node CLL compartment, and could thus provide a specific niche for Notch activation.

\section{The anti-NOTCH1 antibody OMP-52M51 inhibits DLL4-induced Notch activation in CLL}

To evaluate the potential therapeutic targeting of liganddependent Notch signaling in CLL, we considered our functional results above showing that DLL4 promoted effective Notch activation in NOTCH1-mutated CLL cells. Thus, primary CLL cells were treated for $2 \mathrm{~h}$ with the specific anti-NOTCH1 antibody OMP-52M51 before DLL4 stimulation. In all the experiments with OMP$52 \mathrm{M} 51$, an isotype control was added to the untreated condition. Then we monitored the modulation of cleaved Notch 1 by Western blot after $24 \mathrm{~h}$. In contrast to what we observed when CLL cells were stimulated by DLL4 alone, the addition of OMP-52M51 impaired Notch1 DLL4dependent stimulation. This effect was more pronounced in cells from NOTCH1-mutated cases but was also observed in NOTCH1-unmutated ones (Fig. 3a). The treatment with OMP-52M51 only reversed the fraction of cleaved Notch1 increased with the ligand but not the basal active Notch1. Moreover, we analyzed the levels of Notch1-direct target genes after OMP-52M51 treatment and ligand stimulation. 


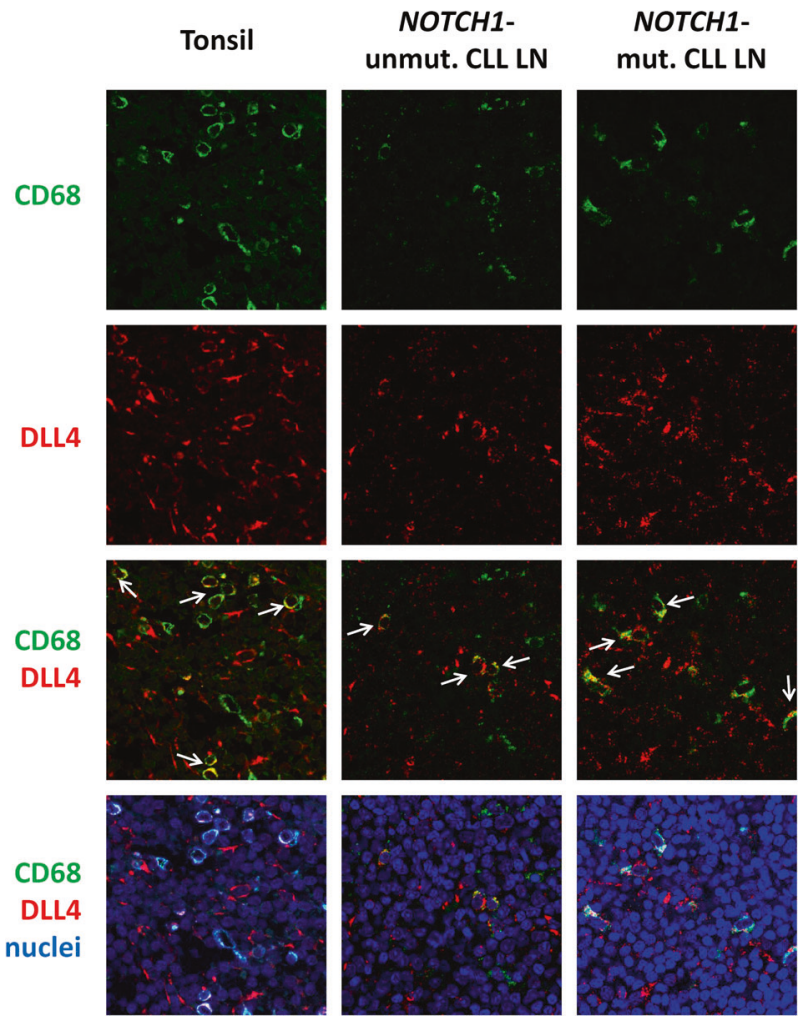

Fig. 2 DLL4 is expressed in CLL lymph nodes. Immunofluorescence staining of tonsils and CLL LN with anti-CD68 (green) and anti-DLL4 (red). Nuclei were stained with Topro-3 (blue). White arrows indicate representative CD68+/DLL4+ cells. Pictures were taken at $\times 63$ magnification in a confocal microscope. Images from a representative case per group are shown (CLL 11 and 19)

Using quantitative PCR, we found that DLL4 increased the mRNA levels of HESI and DTX1 specifically in NOTCH1mutated cases, and OMP-52M51 abrogated almost completely this effect after $24 \mathrm{~h}$ of treatment (Fig. 3b). In contrast, no transcriptional effect of DLL4 was observed in NOTCHI-unmutated cases either with or without antibody treatment.

All these results indicated that the activation of Notch signaling pathway induced by DLL4 in NOTCH1-mutated CLL is stronger than in unmutated cases and could be blocked with a specific Notch1 receptor antibody.

\section{OMP-52M51 inhibits DLL4-induced CLL proliferation}

Since one of the most impressive effects of DLL4 stimulation was the induction of cell proliferation in NOTCH1-mutated CLL, we were interested in exploring the ability of OMP-52M51 to antagonize this effect. Using a CFSE-based assay in long-term cultures, we found that the DLL4-induced increase in cell proliferation in $\mathrm{NOTCHI}$ mutated CLL cells was partially but significantly blocked by OMP-52M51 $(p<0.05$, Fig. 4a). According to these results, we investigated the modulation of three genes known to play a key role in the control of cell proliferation, $M Y C$, NPM1, and CCND1, which have been functionally related to Notch pathway in leukemic cells [10, 17, 18]. Thus, after $72 \mathrm{~h}$, DLL4 significantly upregulated MYC $(p<$ $0.05)$ and NPM1 $(p<0.05)$ in NOTCH1-mutated CLL cells, and $C C N D 1$ showed a similar trend (Fig. 4b). Consistently, OMP-52M51 inhibited the DLL4-induced MYC and NPM1 $(p<0.05)$, and tended to reduce $C C N D 1$ gene expression, specifically in CLL cells carrying NOTCH1 mutation (Fig. $4 b$ ). These results suggested that Notch1 signaling upregulates cell proliferation including $M Y C$ gene expression and that this axis could be therapeutically targeted with an anti-Notch1 antibody.

\section{DLL4 stimulation of NOTCH1-mutated CLL cells induces CXCR4 expression and migration that can be inhibited by OMP-52M51}

Previous work reported that anti-Notch treatment effectively prevents multiple myeloma cell migration by reducing CXCR4 expression at transcriptional level [19]. Given the importance of CXCR4/CXCL12 in CLL biology, we analyzed the effect of Notch ligand stimulation and its therapeutic targeting in this axis. With this objective, we quantified the gene expression levels of $C X C R 4$ by quantitative PCR and protein levels by flow cytometry and assayed CLL cell migration toward CXCL12 after $48 \mathrm{~h}$ of incubation with OMP-52M51 and ligand stimulation. Exposure to DLL4 upregulated CXCR4 mRNA expression as well as protein levels specifically in NOTCH1-mutated CLL cells $(p<0.05)$, together with an induction of the CXCL12-induced migratory capacity of these cells (Fig. 5a-c). Importantly, the anti-Notch1 antibody significantly reversed both CXCR4 gene expression levels $(p<0.01)$ and chemotaxis in DLL4-stimulated NOTCH1mutated CLL $(p<0.05)$.

Furthermore, in addition to CXCL12-induced chemotaxis, we also showed that DLL4 increased CLL cell migration toward CXCL13, another chemokine known to play a role on CLL pathogenesis [20], and similarly to CXCL12, OMP-52M51 blocked this induction in NOTCH1-mutated CLL $(n=6$; Fig. $5 \mathrm{~d})$.

\section{DLL4 increases angiogenic factors in NOTCH1- mutated CLL that can be blocked by OMP-52M51}

Notch pathway is involved in physiological as well as tumor angiogenesis [21]. Therefore, we sought to explore the functional link between Notch1 and angiogenesis in CLL. To this aim, we carried out HUVEC tube formation assays with the supernatants from primary CLL cells exposed to DLL4 in the presence or absence of OMP-52M51. Supernatants from NOTCH1-mutated cells stimulated with DLL4 


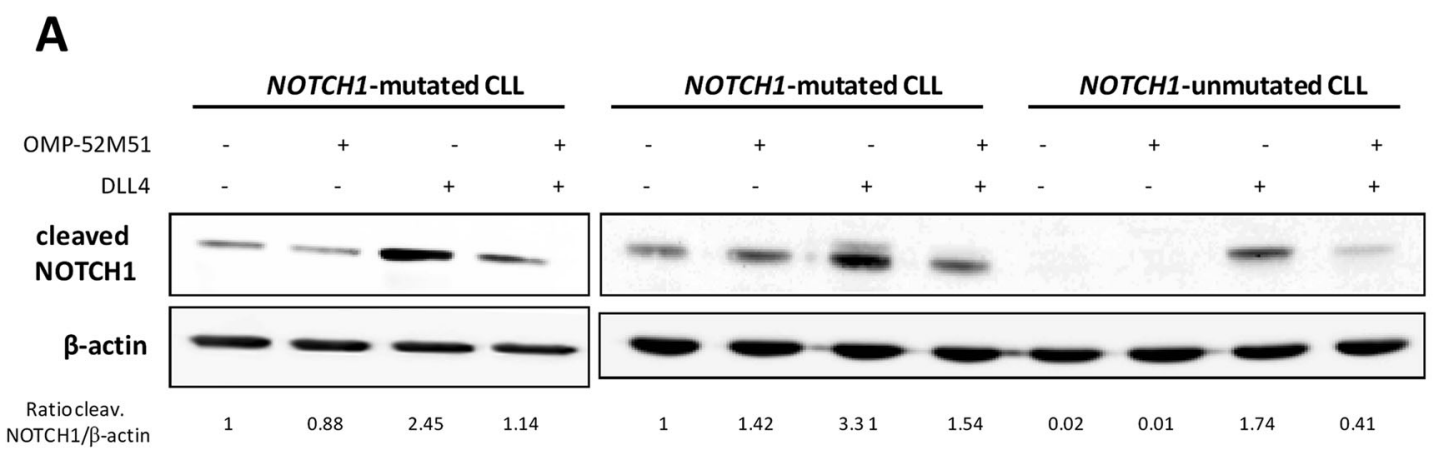

B
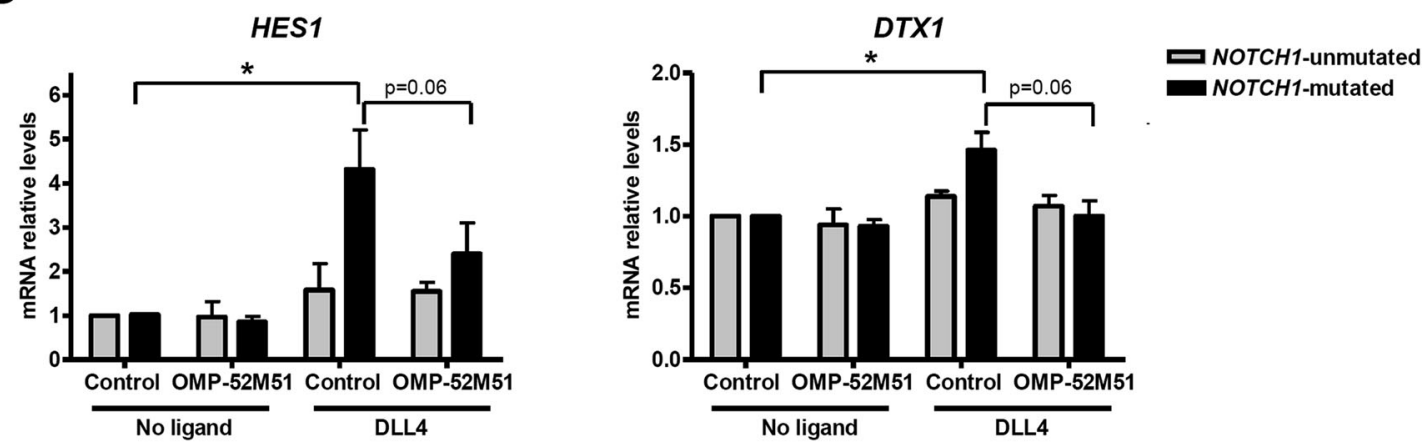

Fig. 3 OMP-52M51 inhibits DLL4-induced Notch activation in CLL. Primary cells from NOTCH1-mutated and NOTCH1-unmutated CLL cases were pretreated for $2 \mathrm{~h}$ with OMP-52M51 before DLL4 stimulation $(4 \mu \mathrm{g} / \mathrm{mL})$ for $24 \mathrm{~h}$. a Cleaved Notch1 was assessed by Western blot and densitometrically quantified. $\beta$-Actin was probed as a loading control. Representative cases are shown (CLL 2, 8, and

18). b Gene expression analysis by quantitative real time PCR of HES1 and DTX1. mRNA relative levels are given as arbitrary units, using untreated condition as a reference. Control: isotype control. Bars represent the mean \pm SEM of NOTCH1-mutated $(n=5)$ and -unmutated $(n=5)$ CLL cases. $p<0.05$

had a proangiogenic effect increasing the number of branch point of HUVEC cells, whereas OMP-52M51 hampered this effect $(p<0.05)$. Again, no effect on NOTCH1-unmutated cases was observed, irrespective of the ligand or antibody exposure (Fig. 6a). To identify possible mediators of this effect, we explored the mRNA expression modulation of two proangiogenic candidate genes for which a functional link with Notch has been proposed: NRARP and $V E G F$ [22-24]. Using quantitative PCR, we showed a significant upregulation of NRARP and VEGFA levels $(p<$ 0.05 ), which was blocked by OMP-52M51 treatment in NOTCH1-mutated CLL cells (Fig. 6b, c). Altogether, these results suggest a functional transcriptional link between Notch1 signaling and aggressiveness-related protumor processes in CLL and that may be disrupted by a Notchtargeted strategy.

\section{Discussion}

NOTCH1 mutations in CLL are activating events that increase the stability of Notch1 intracellular domain [2]. However, these mutations have a weak transforming effect and are expected to be dependent on the presence of Notch

ligands in the microenvironment to trigger and maintain a constitutive Notch1 activation. Accordingly, in vitro studies have shown that crosstalk between tumor CLL cells and accessory cells is required to maintain Notch signaling [8]. However, the microenvironmental cell components as well as the ligands that lead to Notch1 activation in CLL are not yet well established. On the other hand, targeting the connection between the ligand- and the receptor-presenting cell has emerged as a new therapeutic opportunity that also needs to be explored, in particular for the high-risk NOTCH1-mutated CLL patients. In the present work, we have attempted to address both questions using primary CLL cells from both NOTCH1-mutated and -unmutated cases. First, we showed that DLL4 was a potent stimulator of Notch1 signaling mainly in NOTCH1-mutated CLL cells, leading to the activation of some protumor genes and inducing processes that confer aggressiveness to the tumor, such as cell proliferation, migration, and angiogenesis. Second, we identified for the first time an efficient and specific strategy to target this ligand-induced Notch activation with an anti-Notch1 antibody. Our results pointed out that the functional effects of the DLL4-induced stimulation were specific of cells carrying NOTCH1 mutations and barely occurred in unmutated cases without basal 
A
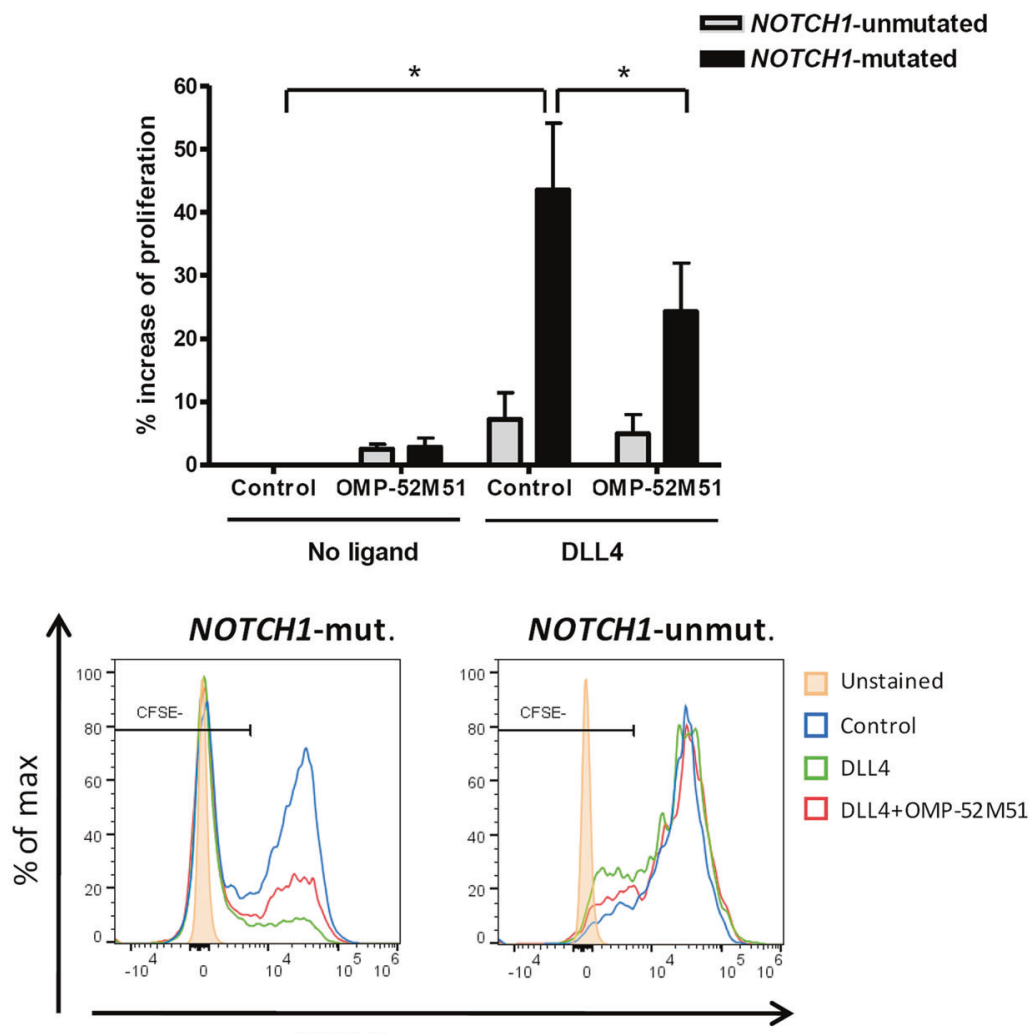

B
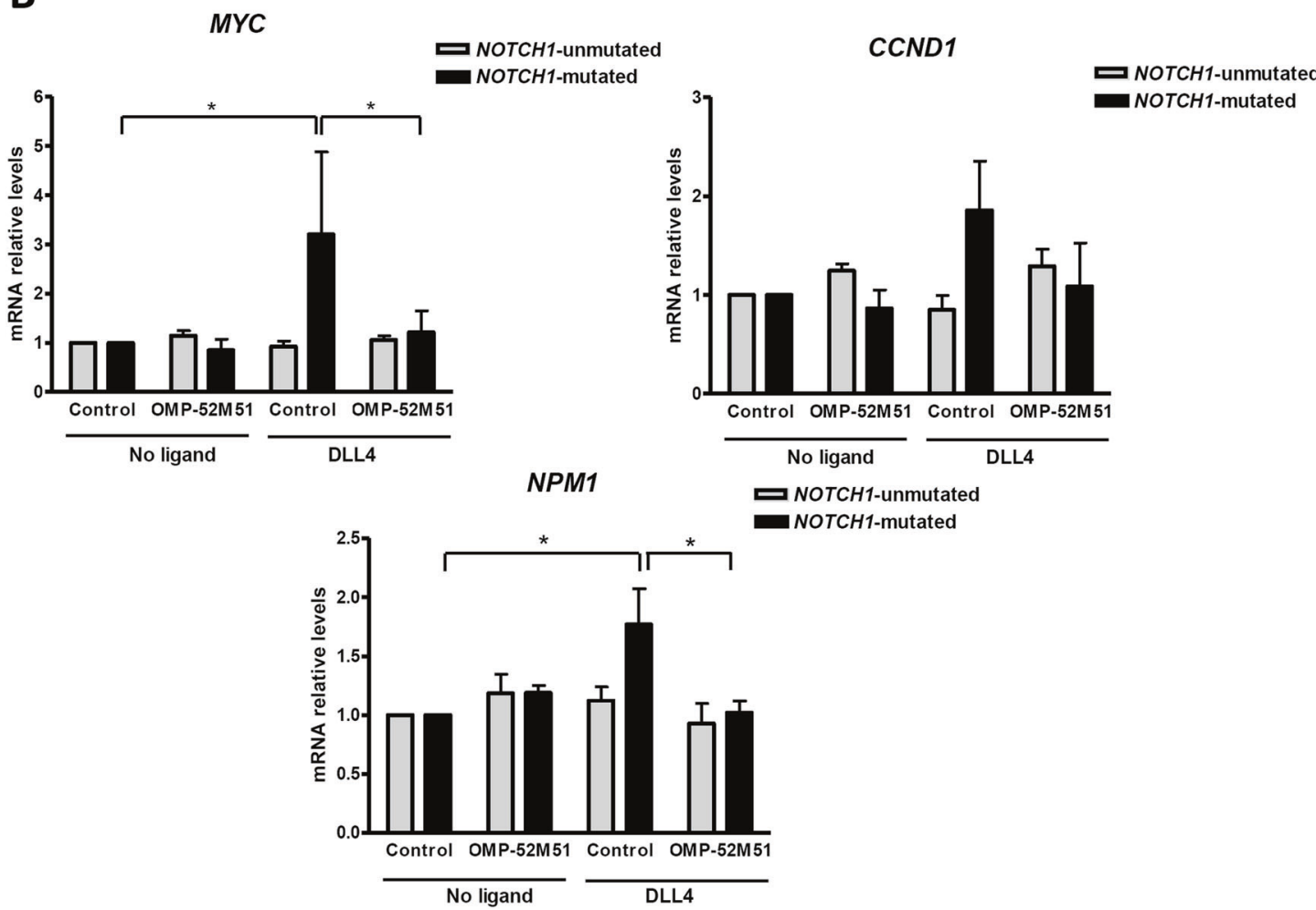

cleaved Notch1. We hypothesized that in NOTCH1-unmutated cells the signaling would not be sustained enough to have a substantial transcriptional and functional impact, as the wild type Notch1 protein has a rapid turnover [25]. Accordingly, NOTCH1 mutations in the PEST domain have been suggested to increase the cleaved Notch1 half-life [2]. 
Fig. 4 OMP-52M51 inhibits DLL4-induced proliferation. a CFSEstained CLL cells were pretreated for $2 \mathrm{~h}$ with OMP-52M51 before DLL4 stimulation $(4 \mu \mathrm{g} / \mathrm{mL})$ for 6 days. Reduction of CFSE fluorescence in viable CLL cells was quantified by flow cytometry. Graph shows the percentage of cell proliferation induction with respect to the unstimulated control. Mean \pm SEM of all the samples analyzed. Bottom panel shows the histograms of CFSE staining in representative CLL cases (CLL 2 and 15). b Cells from NOTCH1-mutated and NOTCH1-unmutated CLL cases were pretreated for $2 \mathrm{~h}$ with OMP52M51 before DLL4 stimulation $(4 \mu \mathrm{g} / \mathrm{mL})$ for $72 \mathrm{~h}$. Gene expression of $M Y C, C C N D 1$, and NPM1 was analyzed by quantitative real time PCR. mRNA relative levels are given as arbitrary units, using untreated cells as a reference. Control: isotype control. Bars represent the mean \pm SEM of NOTCH1-mutated $(n=6)$ and -unmutated $(n=4)$ CLL cases. $p<0.05$

The effect that DLL4 could have in CLL with alternative nonmutational NOTCHI activation [10] needs further validation.

We first investigated the stimulation of CLL cells with the different Notch ligands Jagged1, Jagged2, DLL1, and DLL4. Our results highlighted an important role for the Delta-like ligands DLL4 and DLL1 in CLL, being DLL4 the most potent stimulator of Notch signaling in NOTCH1mutated CLL cells. Interestingly, this DLL4 stimulation was accompanied by a strong increase in CLL cell proliferation and was specific for mutated cases. However, the stimulation induced by DLL1 was also remarkable and its potential effect on CLL Notch1 stimulation cannot be rule out. DLL1 and DLL4 are structurally related and could promote a similar downstream signaling, although it has been reported that the affinity of DLL4 for Notch1 is more than 10-fold tighter than that of DLL1 [26].

In contrast to what happens in other cellular models, in which soluble Notch ligands have an antagonistic effect [27-30], in CLL we showed that both soluble and immobilized DLL4 had an activating effect in Notch1 signaling. It is currently unknown whether any form of soluble (nonmembrane bound) Notch ligand is physiologically present or relevant in the CLL microenvironment. Furthermore, we provided first evidence that DLL4 was expressed in the lymph node CLL compartment, where it could promote Notch activation in vivo. In particular, DLL4 was highly expressed in the vascular endothelium, as described in other tumor models [31], as well as in accompanying histiocytes. Thus, the stimulation of Notch induced by the DLL4 in CLL could be through the interaction of CLL cells with surrounding cells from the microenvironment. These results agree with previous data suggesting that the Notch1 pathway is strongly activated in CLL LN [5, 8], which represent a relevant proliferative niche for the tumor cells [32]. Monocytes/macrophages play a key role in CLL development and progression through their reciprocal molecular interactions $[33,34]$. Our results indicate that the potential role of macrophages in the stimulation of Notch
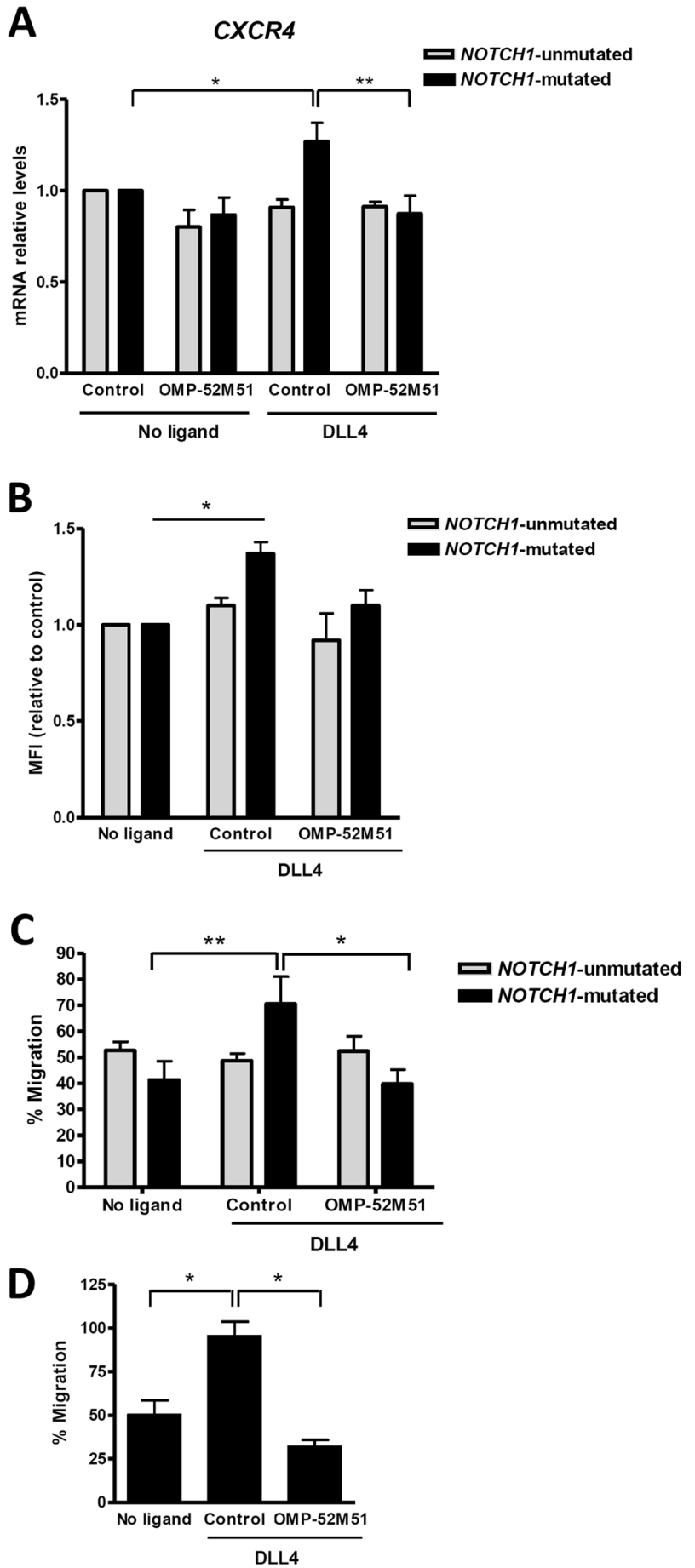

signaling by DLL4 needs further validation. Accordingly, it has been recently described that in bone marrow the monocyte/macrophage- CLL cells crosstalk upregulates NOTCHI and CXCR4, among other genes, suggesting that macrophage targeting can be therapeutically exploited in CLL [35].

Among Notch targeted therapies, GSIs have been the most broadly assessed drugs in different malignancies. In CLL, first attempts to block in vitro Notch1 signaling were 
Fig. 5 OMP-52M51 inhibits DLL4-induced CXCR4 expression and migration. Primary cells from NOTCH1-mutated and NOTCH1unmutated CLL cases were pretreated for $2 \mathrm{~h}$ with OMP-52M51 before DLL4 stimulation $(4 \mu \mathrm{g} / \mathrm{mL})$ for $48 \mathrm{~h}$. a $C X C R 4$ expression was analyzed by quantitative real time PCR. mRNA relative levels are given as arbitrary units, using untreated cells as a reference. b CXCR4 expression was analyzed by flow cytometry $(n=4 \mathrm{NOTCH} 1$-mutated cells; $n=4$ NOTCH1-unmutated cells). CXCR4 expression levels are showed based on the median fluorescence intensity (MFI) on viable cell population, using untreated cells as a reference. c Samples were assayed for chemotaxis toward CXCL12 $(200 \mathrm{ng} / \mathrm{ml})$. Migration is represented as the percentage of migrating cells out of total viable cells added to the transwell. Control: isotype control. Bars represent the mean \pm SEM of NOTCH1-mutated $(n=8)$ and -unmutated $(n=4)$ CLL cases. ${ }^{*} p<0.05 ; * * p<0.01$. d Samples were assayed for chemotaxis toward CXCL13 $(500 \mathrm{ng} / \mathrm{ml})$. Migration is represented as the percentage of migrating cells out of total viable cells added to the transwell. Bars represent the mean \pm SEM of NOTCH1-mutated CLL cases $(n=6) . * p<0.05$

based on the use of these inhibitors, alone or in combination with chemotherapy $[8,11]$. Although these preclinical data showed promising results in CLL NOTCH1-mutated cells, the nonselectivity and gastrointestinal toxicity of GSIs observed in other types of tumors emphasized the need to explore more selective strategies to inhibit Notch1. In this context, specific antibodies against the individual Notch receptors have been developed [14, 15]. Among them, OMP-52M51 is an anti-human Notch1 monoclonal antibody that showed encouraging antitumor efficacy in xenograft models of T-ALL [13]. In NOTCH1-mutated cells, we showed that OMP-52M51 efficiently inhibited soluble DLL4-induced Notch stimulation as well as cell proliferation. Accordingly, OMP-52M51 also reversed the Notchinduced $M Y C, C C N D 1$, and NPM1 gene expression. These three genes are known to play a functional role in the control of cell proliferation in leukemic cells $[10,17,18]$. In particular, MYC and NPMI have been involved in the proliferation advantages of NOTCH1-mutated CLL. MYC is a direct NOTCH1 target and a central oncogene involved in CLL progression [36], as occurs in T-ALL [37]. NPM1 has been identified, together with other genes related to protein biosynthesis, as a targetable $M Y C$-related gene that is overexpressed in NOTCHI-mutated CLL cells [18]. However, these conclusions are limited as a nonphysiological situation of our soluble ligand stimulation system cannot be ruled out.

We also confirmed a functional relationship between Notch1 signaling and the microenvironmental processes related to CLL aggressiveness such as cell migration and angiogenesis, a link that was previously suggested by our group [11]. This axis could be particularly relevant in NOTCH1-mutated cases, as they have been shown to be associated with disease progression and transformation to more aggressive forms [4]. In this line, Notch1 signaling contributes to CCL19-driven migration of CLL cells to tissues [38]. The CXCR4/CXCL12 pathway is also
A
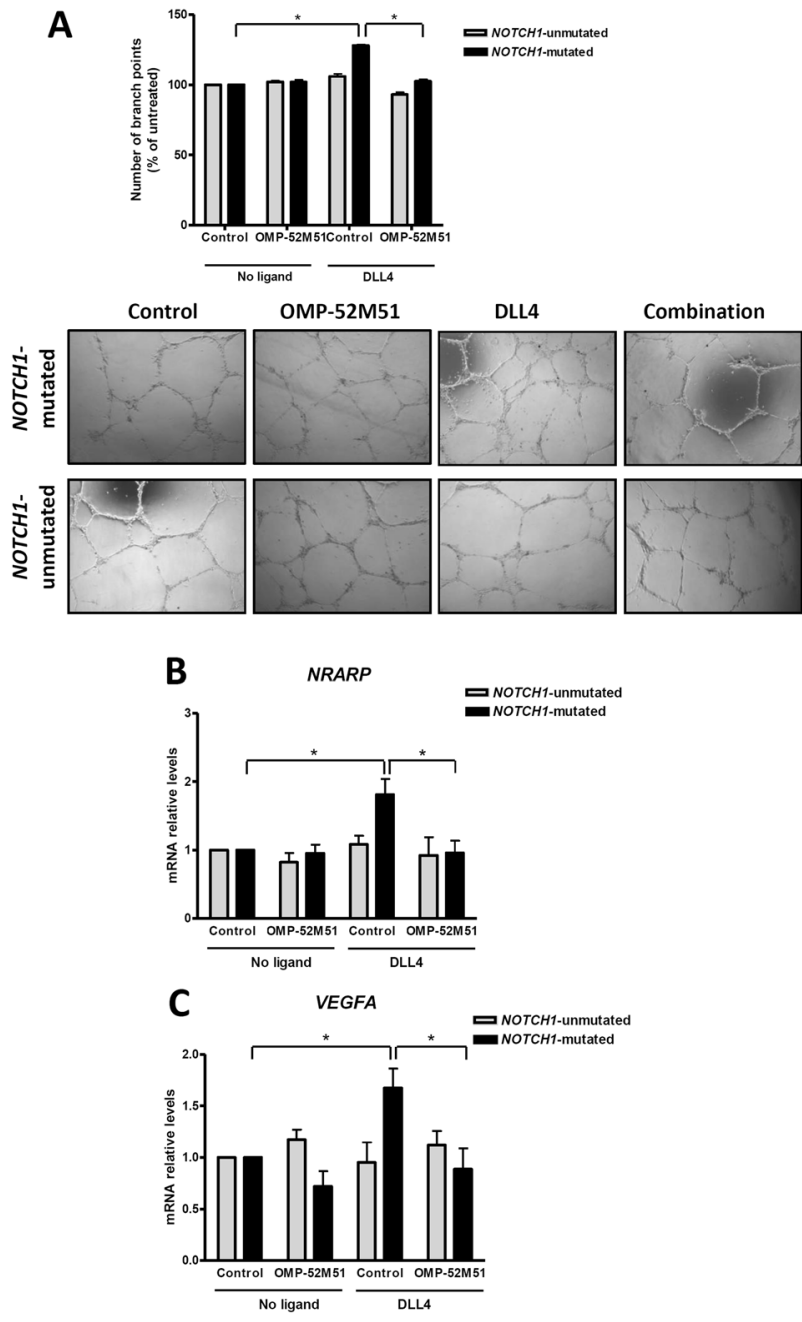

Fig. 6 OMP-52M51 inhibits DLL4-induced angiogenesis. Primary cells from NOTCH1-mutated $(n=6)$ and NOTCH1-unmutated $(n=4)$ CLL cases were pretreated for $2 \mathrm{~h}$ with OMP-52M51 before DLL4 stimulation $(4 \mu \mathrm{g} / \mathrm{mL})$ for $72 \mathrm{~h}$. a Supernatant from CLL cells was harvested after treatment and added to HUVEC cells for $24 \mathrm{~h}$. The number of branch points was quantified as the mean of five randomly chosen fields from each well. Bars represent the mean \pm SEM. ${ }^{*} p<$ 0.05 . Microscope images $(\times 40$ magnification) from a representative case per condition are shown (CLL 2 and 12). b NRARP and VEGFA expression was analyzed by quantitative real time PCR. mRNA relative levels are given as arbitrary units, using untreated cells as a reference. Control: isotype control

fundamental for CLL homing and CXCR4 expression has been related to an increased risk for lymphoid organ infiltration and poor outcome [39]. In this context, CXCR4 has also emerged as a novel NOTCH1 target in CLL [10]. Remarkably, we reported that soluble DLL4-induced CXCR4 expression and migration were both inhibited by OMP-52M51 in NOTCH1-mutated CLL cells. In agreement, Notch inhibition effectively prevents multiple myeloma cell migration by reducing CXCR4 expression at the transcriptional level [19]. However, as the increase of 
CXCR4 by DLL4 is relatively modest compared with the chemotaxis induction, other Notch1-dependent mediators should not be discarded. In this way, the same effect of DLL4 and OMP-52M521 was observed in NOTCH1mutated cell migration toward CXCL13, suggesting that Notch1 signaling would lead to a general increase in NOTCH1-mutated CLL chemotaxis. In parallel, we showed that supernatants from NOTCH1-mutated CLL cells stimulated with DLL4 increased HUVEC tube formation, whereas OMP-52M51 was able to block this proangiogenic effect. This was accompanied by the transcriptional modulation of the angiogenic factors NRARP and VEGFA. It is well established that the Notch pathway is involved in physiological as well as tumor angiogenesis [21]. In acute myeloid leukemia, leukemic cells increased HUVEC tube formation through the activation of the VEGF and DLL4 pathway [40]. In this sense, our results highlight that in CLL might be also a link between DLL4 and VEGF, although the proangiogenic role of other Notch1-targets should also be considered.

In summary, our results suggest that DLL4 expressed by tumor microenvironment could activate Notch signaling in CLL. In addition, we propose a functional link between Notch1 signaling and aggressiveness-related protumor processes in CLL, which could be disrupted by specific Notch-targeting.

\section{Materials and methods}

\section{Isolation and culture of cells}

Primary cells from 20 CLL patients were studied (Table 1). IGHV gene mutational status and NOTCHI mutations were analyzed in previous sequencing studies [2, 4, 5, 41]. Primary cells were isolated from peripheral blood by FicollPaque sedimentation (GE Healthcare, Little Chalfont, UK), cryopreserved and conserved within the Hematopathology collection of our institution registered at the Biobank from Hospital Clínic-IDIBAPS (R121004-094). The ethical approval for this project including the informed consent of the patients was granted following the guidelines of the Hospital Clínic Ethics Committee. Once thawed, cells were cultured at $2 \times 10^{6}$ cells/ml in RPMI 1640 supplemented with $10 \%$ fetal bovine serum (FBS), $2 \mathrm{mM}$ glutamine and $50 \mu \mathrm{g} / \mathrm{ml}$ penicillin-streptomycin (Life Technologies, Carlsbad, CA, USA), in a humidified atmosphere at $37^{\circ} \mathrm{C}$ containing $5 \%$ carbon dioxide.

\section{Notch ligand stimulation and cell treatment}

Recombinant ligands Jagged1, Jagged2, DLL1, and DLL4 (R\&D Systems, Minneapolis, MN, USA) were reconstituted in phosphate buffered saline (PBS). Soluble ligands
( $10 \mu \mathrm{g} / \mathrm{ml}$ for the experiments in Fig. 1 and $4 \mu \mathrm{g} / \mathrm{ml}$ for the other experiments) were let to bind to 12-, 24- or 96-well flat bottom polystyrene culture plates (Corning Inc., Corning, NY, USA) for $4 \mathrm{~h}$ at $4{ }^{\circ} \mathrm{C}$ after a spin down. Without removing the excess of soluble ligands, CLL cells were seeded in the previous plates and, after a centrifugation step, the cultures were incubated for the indicated times. Two hours before stimulation with ligands, CLL cells were incubated with the anti-Notch1 antibody OMP-52M51 (kindly provided by Oncomed Pharmaceuticals, Redwood City, CA, USA) at $25 \mu \mathrm{g} / \mathrm{ml}$ or with an isotype control. Stromal cell lines OP9-DLL1 and -DLL4 cells were generated and grown as described [42]. For the generation of OP9 stromal cell lines expressing human Jagged 1 (OP9JAG1), pLZRS-IRES-eGFP retroviral vectors encoding either human Jag1 and GFP as cell tracer or only GFP were kindly provided by Dr. L. Parreira (Instituto de Histologia e Embriologia, Lisboa, Portugal). Jag1 and GFP retroviral constructs were lipofected (Fugene6, Roche, Basel, Switzerland) into 293T Phoenix-Amphotropic cells and transfected cells were selected with $2.5 \mathrm{mg} / \mathrm{ml}$ puromycin (Sigma-Aldrich, St. Louis, MO, USA) during two weeks. Mouse OP9 BM stromal cells (American Type Culture Collection; ATCC CRL-2749) were transduced by centrifugation in the presence or $8 \mathrm{mg} / \mathrm{ml}$ polybrene. Forty eight hours post transduction, OP9 cells were analyzed for GFP expression by flow cytometry and sorted for homogeneous high expression of GFP. Quantification by flow cytometry of the levels of JAG1, DLL1, and DLL4 confirmed that $100 \%$ of OP9-transfected cells expressed the corresponding ligand (Supplemental Fig. 2).

For stroma cocultures, OP9 cells were plated overnight, and then medium was replaced by CLL cells $\left(2 \times 10^{6}\right.$ cells/ $\mathrm{mL}$ ) previously treated with OMP-52M51 for $2 \mathrm{~h}$, or with untreated cells. After $24 \mathrm{~h}$ of coculture, CLL cells were collected by carefully rinsing the wells without disturbing the stroma monolayer and processed as required.

\section{Protein analysis}

Protein extracts were obtained and processed by western blot as previously described [43]. For protein immunodetection, the following specific primary antibodies were used: cleaved Notch1 (Cell Signaling Technology, Danvers, MA, USA) and $\beta$-actin (Sigma-Aldrich). Anti-rabbit and anti-mouse horseradish peroxidase (HRP)-labeled IgGs (Cell Signaling Technology) were used as secondary antibodies. Chemiluminescence was detected with ECL substrate (Pierce Biotechnology, Rockford, Il., USA) on a miniLAS4000 Fujifilm device (GE Healthcare). Signal was quantified with Image Gauge densitometric software v4.0 (Fujifilm, Tokyo, Japan) and referred to the respective control. 


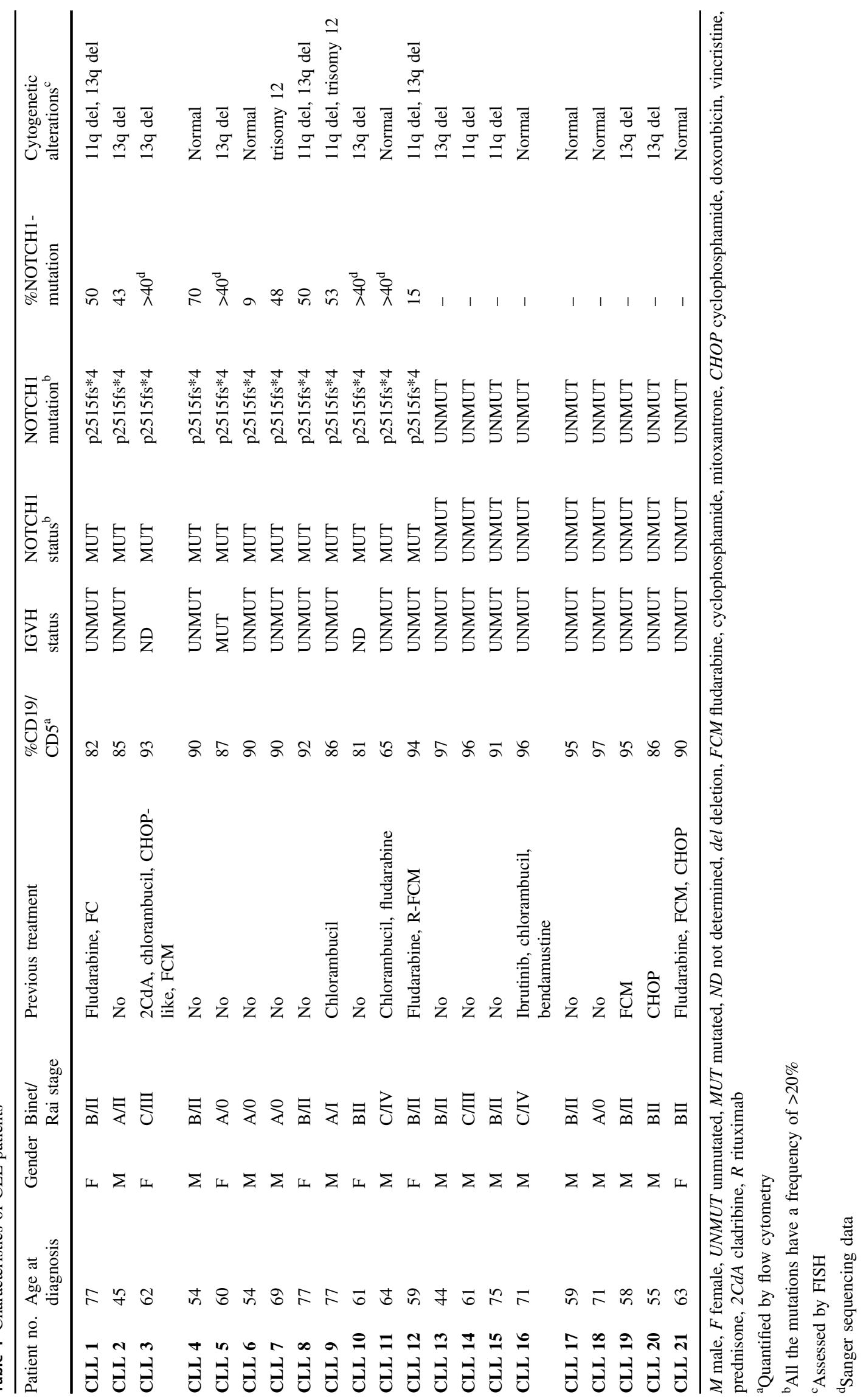




\section{Quantitative real-time PCR}

Total RNA was isolated from CLL cells as previously [11]. cDNA was obtained from $0.5-1 \mu \mathrm{g}$ of DNA-free RNA with the M-MLV reverse transcriptase (Thermo Fisher Scientific, Waltham, MA, USA). Samples were processed to Specific Target Amplification using the Fluidigm PreAmpMaster Mix (Fluidigm Corporation, San Francisco, CA, USA) and the following TaqMan Gene Expression Assays (Thermo Fisher Scientific): HES1, MYC, DTX1, CCND1, NRARP, NPM1, CXCR4, and VEGFA. The relative expression of each gene was quantified by the comparative cycle threshold $(\mathrm{Ct})$ method $(\Delta \Delta \mathrm{Ct})$, using GUSB as endogenous control. To statistically address the effect of DLL4, no-ligand control condition was used as a reference, and to address the effect of OMP-52M51 on DLL4 stimulation, OMP-52M51 plus DLL4 condition was compared with DLL4 control condition.

\section{Immunohistochemistry and confocal microscopy}

Lymph node biopsies from CLL cases were obtained from the Hematopathology collection. Formalin-fixed paraffinembedded tissue slides (serial $8 \mu \mathrm{m}$ sections) were deparaffinised in xylene and etanol-graded series. Tissue antigens were retrieved by boiling during $10-15 \mathrm{~min}$ in sodium citrate $(10 \mathrm{mM}, \mathrm{pH} 6.0)$ and slides were allowed to cool down to room temperature (RT), and then washed in distilled water and PBS. Quenching and permeabilization were carried out using $1 \% \mathrm{H}_{2} \mathrm{O}_{2}$ in $100 \%$ methanol (40 min, RT) and $0.3 \%$ Triton-X-100 (20 min, Sigma-Aldrich) in PBS, respectively. Sections were incubated overnight with the following primary antibodies: anti-human DLL4 (Rabbit, Santa Cruz, Dallas, TX, USA) and anti-human CD68 (Dako, Glostrup, Germany). Background staining was determined by incubating with irrelevant antibodies. Unspecific fluorescence was quenched by incubating with avidin/biotin blocking solutions (Vector Lab, Burlingame, CA, USA). For DLL4 detection, tissue slides were incubated with anti-rabbit IgG-HRP antibody (in 5\% BSA in PBS, Dako) and then, the signal was amplified by incubation with the Cyanine-3 Tyramide Signal Amplification Kit (TSA; NEL 744, Perkin Elmer, Waltham, MA, USA). For CD68 immunodetection, a biotinylated anti-mouse IgG (Vector Lab) was added following incubation with avidin/ biotin complex (Elite Vectastain ABC Complex kit, Vector Lab). Next, signal was developed by adding Alexa-488conjugated streptavidin. Nuclei were stained with Topro-3 (Invitrogen, Carlsbad, CA, USA) and mounted with Fluoromount-G (Southern Biotech., Birmingham, AL, USA). Images were acquired using a LSM510 laser scan confocal microscope (Zeiss, Oberkochen, Germany) coupled to an Axiovert 200 (Zeiss) microscope, using $\times 63$
Plan-Neofluar magnification. Images were processed using ImageJ and Adobe Photoshop CS3 software.

\section{CFSE-based proliferation assay}

CLL cells were stained with carboxyfluorescein diacetate succinimidyl ester (CFSE; Thermo Fisher Scientific) as described [16] with some modifications. Briefly, cells at $10 \times 10^{6} / \mathrm{ml}$ were incubated for $10 \mathrm{~min}$ in the dark with $0.5 \mu \mathrm{M}$ CFSE. Then, an equal volume of FBS was added for another $10 \mathrm{~min}$ and the cells were washed twice. CFSElabeled CLL cells were cultured in an enriched RPMI 1640 medium used for long-term cultures. Specifically, this enriched medium contained 15\% heat-inactivated FBS, 1X ITS (insulin, transferrin, selenium cocktail; Biowhittaker, Walkersville, MD, USA), $1 \mathrm{M}$ pH7.3 HEPES, $1 \mathrm{X}$ nonessential aminoacid solution (Thermofisher Scientific), $100 \mathrm{mM}$ sodium pyruvate, $1 \mathrm{X}$ 2-mercaptoethanol (Thermofisher Scientific) and $50 \mathrm{mg} / \mathrm{mL}$ gentamicin sulfate (Biowhittaker). Recombinant human IL-15 (R\&D Systems) and the TLR9 ligand CpG oligonucleotide (ODN-2006; Invivogen, San Diego, CA, USA) were added at final concentrations of $15 \mathrm{ng} / \mathrm{ml}$ and $0.2 \mu \mathrm{M}$, respectively. After 6 days of incubation, cells were collected and stained with Annexin-V-Pacific Blue (PB; Thermo Fisher Scientific) and CD19-PE (Becton Dickinson, Franklin Lakes, NJ, USA) and acquired in an Attune acoustic cytometer (Thermo Fisher Scientific). CLL proliferation was measured as the reduction on CFSE fluorescence based on the median fluorescence intensity (MFI) on the CD19+ and Annexin-V negative cell population. Data analysis was performed using FlowJo v10.0.7 software (FlowJo, Ashland, OR, USA).

\section{CXCR4 staining}

CLL cells were stained with the Live/Dead ${ }^{\circledR}$ Fixable Aqua Dead Cell Stain Kit (Life Technologies) and blocked with $10 \%$ mouse serum (Sigma). Then, samples were CXCR4$\mathrm{PE}$ or mouse IgG1 isotype- PE (Becton Dickinson) labeled and acquired in an Attune acoustic cytometer (Thermo Fisher Scientific). CXCR4 expression levels are showed based on the MFI on viable cell population, using untreated cells as a reference.

\section{Chemotaxis assay}

After $48 \mathrm{~h}$ of incubation with Notch ligands and OMP52M51, CLL cells were washed twice and serum starved for $1.5 \mathrm{~h}$ in FBS-free RPMI $\left(10^{7}\right.$ cells $\left./ \mathrm{ml}\right)$. One hundred $\mu \mathrm{l}$ of diluted cells $\left(5 \times 10^{6}\right.$ cells $/ \mathrm{ml}$ with $0.5 \%$ BSA in RPMI) were added to the top chambers of transwell culture polycarbonate inserts with $6.5 \mathrm{~mm}$ diameter and $5 \mu \mathrm{m}$ pore size (Corning Inc.). Inserts had been previously transferred to 
wells containing $600 \mu \mathrm{l}$ of $0.5 \%$ BSA in RPMI with $200 \mathrm{ng} / \mathrm{ml}$ of CXCL12 or $500 \mathrm{ng} / \mathrm{ml}$ of CXCL13. Total cell count was obtained from adding $100 \mu \mathrm{l}$ of cell suspension to wells containing $600 \mu \mathrm{l}$ of $0.5 \%$ BSA in RPMI. After $4 \mathrm{~h}$, $100 \mu \mathrm{l}$ were collected in triplicate from each lower chamber and total wells, and viable cells were gated and counted on an Attune cytometer (Thermo Fisher Scientific) under constant flow rate. Migration was represented as percentage of migrating cells out of total viable cells added to the transwell.

\section{HUVEC tube formation assay}

HUVEC cells, kindly provided by Dr MC Cid (IDIBAPS), were cultured as previously described [44]. Supernatant from CLL cells $\left(2 \times 10^{6}\right.$ cells $\left./ \mathrm{ml}\right)$ was harvested after $72 \mathrm{~h}$ of incubation with OMP-52M51 and ligand stimulation. Twenty-four-well plates were plated with $300 \mu \mathrm{l}$ of Matrigel (Becton Dickinson). Subsequently, $500 \mu$ of the supernatant of interest and $500 \mu \mathrm{l}$ of HUVEC cells $\left(0.8 \times 10^{5}\right.$ cells $/ \mathrm{ml}$ ) were added into each culture well. For the control, the supernatant was substituted for complete RPMI medium. After $24 \mathrm{~h}$ of incubation, the number of branch points was counted and quantified as the mean of five randomly chosen fields from each well. Pictures were taken at $\times 40$ magnification in a DM IL LED microscope (Leica, Solms, Germany) coupled to a DFC295 camera with Leica Application Suite v3.7 software (Leica).

\section{Statistical analyses}

Data are represented as mean \pm SEM of all cases. Statistics were calculated using GraphPadPrism 4.0 software (GraphPad Software, La Jolla, CA, USA). Nonparametric Wilcoxon signed rank test was used to compare the median of a set of samples to a theoretical value. Comparison between means of two sets of samples was evaluated by nonparametric Wilcoxon matched-pairs test or Mann-Whitney test. Results were considered statistically significant when $p$-value $<0.05$ $\left({ }^{*} p<0.05, * * p<0.01, * * * p<0.001\right)$.

\footnotetext{
Acknowledgements The authors would like to thank Sandra Cabezas and Laura Jiménez for their technical support. We also thank Dr Maria $\mathrm{C}$ Cid for providing HUVEC cells. We are very grateful to the CLL Genome Consortium and all CLL patients who have participated in this study. This work was carried out at the Centre Esther Koplowitz, Barcelona. This study was supported by research funding from Ministerio de Ciencia e Innovación (SAF2015-31242-R and RTI2018094584-B-I00 to DC and SAF2016-75442-R to MLT), Departament de Salut (SLT002-16-00350) to DC, the ISCII-Sub-Directorate General for Evaluation (PM15/00007), which are part of Plan Nacional de $\mathrm{I}+\mathrm{D}+\mathrm{I}$ and are co-financed by and the European Regional Development Fund (FEDER-“Una manera de hacer Europa"), Generalitat de Catalunya (2014SGR967 and 2017SGR1009) and CIBERONC (CB16/12/00334, CB16/12/00225 and CB16/12/00236). ELV and NG are recipients of predoctoral fellowships from Ministerio de Ciencia e
}

Innovación (FPI program), and from Agaur, Generalitat de Catalunya, respectively.

\section{Compliance with ethical standards}

Conflict of interest The authors declare that they have no conflict of interest.

Publisher's note Springer Nature remains neutral with regard to jurisdictional claims in published maps and institutional affiliations.

Open Access This article is licensed under a Creative Commons Attribution 4.0 International License, which permits use, sharing, adaptation, distribution and reproduction in any medium or format, as long as you give appropriate credit to the original author(s) and the source, provide a link to the Creative Commons license, and indicate if changes were made. The images or other third party material in this article are included in the article's Creative Commons license, unless indicated otherwise in a credit line to the material. If material is not included in the article's Creative Commons license and your intended use is not permitted by statutory regulation or exceeds the permitted use, you will need to obtain permission directly from the copyright holder. To view a copy of this license, visit http://creativecommons. org/licenses/by/4.0/.

\section{References}

1. Fabbri G, Rasi S, Rossi D, Trifonov V, Khiabanian H, Ma J, et al. Analysis of the chronic lymphocytic leukemia coding genome: role of NOTCH1 mutational activation. J Exp Med. 2011;208:1389-401.

2. Puente XS, Pinyol M, Quesada V, Conde L, Ordonez GR, Villamor $\mathrm{N}$, et al. Whole-genome sequencing identifies recurrent mutations in chronic lymphocytic leukaemia. Nature. 2011;475:101-5.

3. Rossi D, Rasi S, Fabbri G, Spina V, Fangazio M, Forconi F, et al. Mutations of NOTCH1 are an independent predictor of survival in chronic lymphocytic leukemia. Blood. 2012;119:521-9.

4. Villamor N, Conde L, Martinez-Trillos A, Cazorla M, Navarro A, Bea $\mathrm{S}$, et al. NOTCH1 mutations identify a genetic subgroup of chronic lymphocytic leukemia patients with high risk of transformation and poor outcome. Leukemia. 2013;27:1100-6.

5. Puente XS, Bea S, Valdes-Mas R, Villamor N, Gutierrez-Abril J, Martin-Subero JI, et al. Non-coding recurrent mutations in chronic lymphocytic leukaemia. Nature. 2015;526:519-24.

6. Belver L, Ferrando A. The genetics and mechanisms of T cell acute lymphoblastic leukaemia. Nat Rev Cancer. 2016;16:494-507.

7. Bray SJ. Notch signalling: a simple pathway becomes complex. Nat Rev Mol Cell Biol. 2006;7:678-89.

8. Arruga F, Gizdic B, Serra S, Vaisitti T, Ciardullo C, Coscia M, et al. Functional impact of NOTCH1 mutations in chronic lymphocytic leukemia. Leukemia. 2014;28:1060-70.

9. Rosati E, Sabatini R, Rampino G, Tabilio A, Di IM, Fettucciari K, et al. Constitutively activated Notch signaling is involved in survival and apoptosis resistance of B-CLL cells. Blood. 2009;113:856-65.

10. Fabbri G, Holmes AB, Viganotti M, Scuoppo C, Belver L, Herranz D, et al. Common nonmutational NOTCH1 activation in chronic lymphocytic leukemia. Proc Natl Acad Sci USA. 2017;114:E2911-E2919.

11. Lopez-Guerra M, Xargay-Torrent S, Rosich L, Montraveta A, Roldan J, Matas-Cespedes A, et al. The gamma-secretase inhibitor PF-03084014 combined with fludarabine antagonizes migration, invasion and angiogenesis in NOTCH1-mutated CLL cells. Leukemia. 2015;29:96-106.

12. Andersson ER, Lendahl U. Therapeutic modulation of Notch signalling-are we there yet? Nat Rev Drug Disco. 2014;13:357-78. 
13. Agnusdei V, Minuzzo S, Frasson C, Grassi A, Axelrod F, Satyal $\mathrm{S}$, et al. Therapeutic antibody targeting of Notch1 in T-acute lymphoblastic leukemia xenografts. Leukemia. 2014;28:278-88.

14. Aste-Amezaga M, Zhang N, Lineberger JE, Arnold BA, Toner TJ, $\mathrm{Gu} \mathrm{M}$, et al. Characterization of Notch1 antibodies that inhibit signaling of both normal and mutated Notch1 receptors. PLoS ONE. 2010;5:e9094.

15. Wu Y, Cain-Hom C, Choy L, Hagenbeek TJ, de Leon GP, Chen $\mathrm{Y}$, et al. Therapeutic antibody targeting of individual Notch receptors. Nature. 2010;464:1052-7.

16. Mongini PK, Gupta R, Boyle E, Nieto J, Lee H, Stein J, et al. TLR-9 and IL-15 synergy promotes the in vitro clonal expansion of chronic lymphocytic leukemia B Cells. J Immunol. 2015;195:901-23.

17. Guo D, Ye J, Dai J, Li L, Chen F, Ma D, et al. Notch-1 regulates Akt signaling pathway and the expression of cell cycle regulatory proteins cyclin D1, CDK2 and p21 in T-ALL cell lines. Leuk Res. 2009;33:678-85.

18. Pozzo F, Bittolo T, Vendramini E, Bomben R, Bulian P, Rossi FM, et al. NOTCH1-mutated chronic lymphocytic leukemia cells are characterized by a MYC-related overexpression of nucleophosmin 1 and ribosome-associated components. Leukemia. 2017;31:2407-15.

19. Mirandola L, Apicella L, Colombo M, Yu Y, Berta DG, Platonova $\mathrm{N}$, et al. Anti-notch treatment prevents multiple myeloma cells localization to the bone marrow via the chemokine system CXCR4/SDF-1. Leukemia. 2013;27:1558-66.

20. Burkle A, Niedermeier M, Schmitt-Graff A, Wierda WG, Keating MJ, Burger JA. Overexpression of the CXCR5 chemokine receptor, and its ligand, CXCL13 in B-cell chronic lymphocytic leukemia. Blood. 2007;110:3316-25.

21. Phng LK, Gerhardt H. Angiogenesis: a team effort coordinated by notch. Dev Cell. 2009;16:196-208.

22. Krebs LT, Deftos ML, Bevan MJ, Gridley T. The Nrarp gene encodes an ankyrin-repeat protein that is transcriptionally regulated by the notch signaling pathway. Dev Biol. 2001;238:110-9.

23. Lamar E, Deblandre G, Wettstein D, Gawantka V, Pollet N, Niehrs C, et al. Nrarp is a novel intracellular component of the notch signaling pathway. Genes Dev. 2001;15:1885-99.

24. Thurston G, Kitajewski J. VEGF and delta-notch: interacting signalling pathways in tumour angiogenesis. $\mathrm{Br} \mathrm{J}$ Cancer. 2008;99:1204-9.

25. Arruga F, Vaisitti T, Deaglio S. The NOTCH pathway and its mutations in mature B cell malignancies. Front Oncol. 2018;8:550.

26. Andrawes MB, Xu X, Liu H, Ficarro SB, Marto JA, Aster JC, et al. Intrinsic selectivity of Notch 1 for delta-like 4 over delta-like 1. J Biol Chem. 2013;288:25477-89.

27. Beckstead BL, Santosa DM, Giachelli CM. Mimicking cell-cell interactions at the biomaterial-cell interface for control of stem cell differentiation. J Biomed Mater Res A. 2006;79:94-103.

28. Kangsamaksin T, Murtomaki A, Kofler NM, Cuervo H, Chaudhri RA, Tattersall IW, et al. NOTCH decoys that selectively block DLL/NOTCH or JAG/NOTCH disrupt angiogenesis by unique mechanisms to inhibit tumor growth. Cancer Disco. 2015;5:182-97.

29. Scehnet JS, Jiang W, Kumar SR, Krasnoperov V, Trindade A, Benedito R, et al. Inhibition of Dll4-mediated signaling induces proliferation of immature vessels and results in poor tissue perfusion. Blood. 2007;109:4753-60.

30. Varnum-Finney B, Wu L, Yu M, Brashem-Stein C, Staats S, Flowers D, et al. Immobilization of notch ligand, delta-1, is required for induction of notch signaling. J Cell Sci. 2000;113(Pt 23):4313-8.

31. Patel NS, Li JL, Generali D, Poulsom R, Cranston DW, Harris AL. Up-regulation of delta-like 4 ligand in human tumor vasculature and the role of basal expression in endothelial cell function. Cancer Res. 2005;65:8690-7.

32. Herishanu Y, Perez-Galan P, Liu D, Biancotto A, Pittaluga S, Vire $\mathrm{B}$, et al. The lymph node microenvironment promotes B-cell receptor signaling, NF-kappaB activation, and tumor proliferation in chronic lymphocytic leukemia. Blood. 2011;117:563-74.

33. Galletti G, Caligaris-Cappio F, Bertilaccio MT. B cells and macrophages pursue a common path toward the development and progression of chronic lymphocytic leukemia. Leukemia. 2016;30:2293-301.

34. Hanna BS, McClanahan F, Yazdanparast H, Zaborsky N, Kalter V, Rossner PM, et al. Depletion of CLL-associated patrolling monocytes and macrophages controls disease development and repairs immune dysfunction in vivo. Leukemia. 2016;30:570-9.

35. Galletti G, Scielzo C, Barbaglio F, Rodriguez TV, Riba M, Lazarevic D, et al. Targeting macrophages sensitizes chronic lymphocytic leukemia to apoptosis and inhibits disease progression. Cell Rep. 2016;14:1748-60.

36. Fabbri $\mathrm{G}$, Khiabanian $\mathrm{H}$, Holmes AB, Wang J, Messina M, Mullighan CG, et al. Genetic lesions associated with chronic lymphocytic leukemia transformation to Richter syndrome. J Exp Med. 2013;210:2273-88.

37. Palomero T, Lim WK, Odom DT, Sulis ML, Real PJ, Margolin A, et al. NOTCH1 directly regulates c-MYC and activates a feedforward-loop transcriptional network promoting leukemic cell growth. Proc Natl Acad Sci USA. 2006;103:18261-6.

38. Arruga F, Gizdic B, Bologna C, Cignetto S, Buonincontri R, Serra $\mathrm{S}$, et al. Mutations in NOTCH1 PEST-domain orchestrate CCL19driven homing of chronic lymphocytic leukemia cells by modulating the tumor suppressor gene DUSP22. Leukemia. 2017;31:1882-93.

39. Calissano C, Damle RN, Hayes G, Murphy EJ, Hellerstein MK, Moreno $\mathrm{C}$, et al. In vivo intraclonal and interclonal kinetic heterogeneity in B-cell chronic lymphocytic leukemia. Blood. 2009;114:4832-42.

40. Zhang J, Ye J, Ma D, Liu N, Wu H, Yu S, et al. Cross-talk between leukemic and endothelial cells promotes angiogenesis by VEGF activation of the Notch/Dl14 pathway. Carcinogenesis. 2013;34:667-77.

41. Quesada V, Conde L, Villamor N, Ordonez GR, Jares P, Bassaganyas L, et al. Exome sequencing identifies recurrent mutations of the splicing factor SF3B1 gene in chronic lymphocytic leukemia. Nat Genet 2011;44:47-52.

42. Ayllon V, Bueno C, Ramos-Mejia V, Navarro-Montero O, Prieto $\mathrm{C}$, Real PJ, et al. The Notch ligand DLL4 specifically marks human hematoendothelial progenitors and regulates their hematopoietic fate. Leukemia. 2015;29:1741-53.

43. Xargay-Torrent S, Lopez-Guerra M, Rosich L, Montraveta A, Roldan J, Rodriguez V, et al. The splicing modulator sudemycin induces a specific antitumor response and cooperates with ibrutinib in chronic lymphocytic leukemia. Oncotarget. 2015;6:22734-49.

44. Rosich L, Montraveta A, Xargay-Torrent S, Lopez-Guerra M, Roldan J, Aymerich M, et al. Dual PI3K/mTOR inhibition is required to effectively impair microenvironment survival signals in mantle cell lymphoma. Oncotarget. 2014;5:6788-800. 